\title{
A CROSS-SECTIONAL STUDY ON ADHERENCE TO LIFESTYLE MODIFICATION AMONG KNOWN HYPERTENSIVE PATIENTS IN UDUPI DISTRICT
}

\author{
PRASHANTH SHETTY ${ }^{1}$, KARTHIK RAO N ${ }^{2 *}$, GURUKANTH RAU N ${ }^{3}$, SANJAY M PATTANSHETTY ${ }^{4}$, DIVYA KARANTH ${ }^{5}$ \\ ${ }^{1}$ Department of Medicine, Vinaya Hospital, Kundapura, Karnataka, India. ${ }^{2}$ Department of Medicine, K S Hegde Medical Academy, \\ Mangaluru, Karnataka, India. ${ }^{3}$ Department of Medicine, Srinivas Medical College and Research Institute, Mangalore, Karnataka, India. \\ ${ }^{4}$ Department of Medicine, Prasanna School of Public Health, Manipal, Karnataka, India. ${ }^{5}$ Department of Medicine, Kasturba Medical \\ College, Manipal, Karnataka, India. Email: karthikrao85@gmail.com \\ Received: 10 April 2021, Revised and Accepted: 14 May 2021
}

\section{ABSTRACT}

Objectives: Hypertension is the more prevalent non-communicable disease and is the major risk factors for the cardiovascular disease. Lifestyle modification plays a very important role in controlling or management of the hypertension. Hence, aim of this study is to assess the adherence and non-adherence to lifestyle modification among known hypertensive patients those who are visiting secondary care hospitals in Udupi District.

Methods: This was a multi-centric hospital based cross-sectional study conducted at three secondary care hospitals. Samples were collected through convenient sampling. Standardized questionnaire used to collect data. Associations are obtained the help of frequencies, prevalence, and mean values, ANOVA test, Chi-square, and binary logistic regression were used for the analysis.

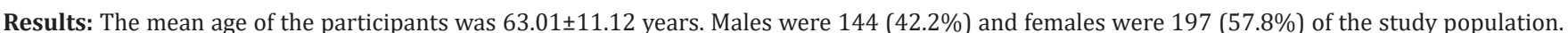
It was found that the self-assessment is influenced by education level of participant $(\mathrm{p}=0.003)$ and time elapsed since diagnosis of hypertension $(\mathrm{p}<0.001)$. Majority of the participants from age group of 34 to 48 and 49 to 63 had good adherence to exercise, that is, 70.4\% (19) and 74.6\% (100), respectively, $(\mathrm{p}=0.001)$. Participants with awareness regarding risk factors and complications of hypertension showed good adherence to exercise. The patients, who adhered to exercise, also consumed less quantity of salt.

Conclusion: Instilling positivity in mind of the patient regarding outcome of treatment and lifestyle modifications can help in controlling the high blood pressure and there by prevent cardiovascular and renal disease in the whole population.

Keywords: Life style, Hypertension, Adherence, Risk factors.

(C) 2021 The Authors. Published by Innovare Academic Sciences Pvt Ltd. This is an open access article under the CC BY license (http://creativecommons.org/ licenses/by/4.0/) DOI: http://dx.doi.org/10.22159/ajpcr.2021v14i7.41828. Journal homepage: https://innovareacademics.in/journals/index.php/ajpcr

\section{INTRODUCTION}

A large proportion of deaths and disability around the world is accounted by cardiovascular disease (CVD) and has become a barrier to sustainable human development. CVD accounts for approximately 17.7 million of death per year worldwide. Non-Communicable Disease has been recognized in the third Sustainable Development Goal, that is, reduction in premature mortality due to non-communicable disease [1].

By 2025 , it is projected that $29 \%$ of the world's population will have hypertension. High blood pressure is ranked as the third most risk factor for attributable burden of disease in South Asia [2]. In India, a recent study has shown that the prevalence of hypertension is $25 \%$ in urban adults and $10-15 \%$ among rural adults. Hypertension accounts for $17.9 \%$ and $34.6 \%$ of population attributable risk factors for coronary artery disease and stroke, respectively $[3,4]$. The dietary approach to stop high blood pressure (DASH) in their study showed that a diet which consists of fruits, vegetables, and low-fat dairy products significantly results in the lower blood pressure [5]. In 1940, Ambard and Beaujard suggested that there was a significant association between salt intake and hypertension. It is one of the behavioral risk factors for hypertension and can be easily modified [6].

The relation between alcohol smoking and hypertension is definite and has been documented in many studies. The persons who smoke have a higher risk of developing hypertension over the time. It is more controllable and preventable risk factors for hypertension [7]. The other risk factor for hypertension is physical inactivity. By increasing the blood flow to the skeletal and cardiac muscles, exercise promotes the angiogenesis [8]. Lifestyle modification helps to improve the risk reduction related to hypertension (HTN) by modifying those factors as; diet, salt intake, alcohol, smoking, and exercise [9].

Hypertensive patients must have the knowledge to be able to define their condition, to evaluate the risk factors, about regular monitoring of blood pressure which helps in adherence to antihypertensive medication. Some of the recent studies have also found that the healthcare practitioners did not sufficiently inform patients about the disease, risk factors, and necessary lifestyle modification. Lack of knowledge and awareness among the HTN patients are seen both in rural an urban environment [10]. The adherence to lifestyle modification is neglected due to lack of knowledge and poor awareness and only a few studies conducted to know the adherence to lifestyle modification. Nonadherence is one of the biggest hindrances in controlling HTN.

Hence, aim of this study is to assess the adherence and non-adherence to lifestyle modification among known hypertensive patients those who are visiting secondary care hospitals in Udupi District and also to estimate the prevalence of adherence and non-adherence to lifestyle modification in known hypertensive patient.

\section{METHODS}

This study was carried out at three secondary care hospitals in Udupi district, one hospital from each taluk. All the three were a private hospital. They are Dr. T M A Pai Rotary Hospital, Karkala (Udupi), Dr. T M A Pai Hospital, Udupi (Udupi), Vinaya Hospital, Kundapura (Udupi). Approval was obtained from the Institutional Ethics Committee 
of Kasturba Medical College, Manipal University [KMC IEC 3/2018]. It was Multi-Centric Cross-Sectional Study and the duration of the study is 6 months, that is, Jan-2018-Jun-2018. A total of 341 adult hypertensive patients attending the OPDs of the department of medicine of the three secondary care hospitals were selected and enrolled. Study variables included socio-demographic factors, knowledge regarding HTN, perception regarding HTN, depression, healthcare support, and lifestyle modifications such as smoking, alcohol, diet, salt intake, and exercise. Inclusion criteria included all the HTN patients above 18 years under antihypertensive medications for at least 6 months before the start of the study. Exclusion criteria included individuals diagnosed of having cerebrovascular accident (Stroke) and comatose individuals selfadministered questionnaire. The questionnaire included 43 questions. The dimensions used in the questionnaire were socio-demographic profile, knowledge, and perception about HTN and lifestyle modification with regard to HTN.

The study protocol was submitted to the institutional ethics committee. After obtaining approval from the ethics committee, permission was taken from all the three hospital administrations, unit head of medicine department. OPD is visited with prior appointment and hypertensive patients were approached. The aim and objectives of the study were explained to patients in a language that they can understand. Participant information sheet was provided to participants. A written informed consent form is obtained from the participants. A structured questionnaire was administered to the patient. The questionnaire included about socio-demographic factors, knowledge, and perception regarding HTN and lifestyle modification. Data regarding demographic knowledge, lifestyle modification in HTN, were obtained.

Excel Spreadsheet was used for entering the collected data. Analysis of quantitative data was done using SPSS 27.0 software. It is done by entering coded data and tables were generated in SPSS. Descriptive analysis was done to find out the mean, prevalence, and frequencies of the associated socio-demographic correlates, ANOVA test, Chi-square test, Independent sample t-test, and binary logistic regression were used to find out the association between the socio-demographic correlates, education, knowledge of HTN, education, and lifestyle modification. For all this statistical tests, $\mathrm{p}<0.05$ was taken as significant.

\section{RESULTS}

The total sample is composed of 341 participants (known cases of HTN) from Udupi district. The mean age of the participants is $63.01 \pm 11.12$ years. Single people develop HTN at a much younger age than married people do $(p<0.001)$. There was an association between age and religion, which showed that Hindus and Christians develop HTN at a later age, when compared with Muslims $(p=0.023)$. The more educated a person is, the earlier in life he/she develops HTN ( $p<0.001)$. Either this could be due to lifestyle choices of educated people, or it could also indicate an under-diagnosis of HTN in lesser/uneducated people due to lack of awareness. People who are self-employed or laborers were at least 5 years younger than the others were $(p<0.001)$. Participants from the lower-lower class, who had HTN, had a mean age of $42.50 \pm 14.85$ years, which were significantly lower (p-0.025) than people from other socio-economic strata of society (Tables 1 and 2).

The participants included in the study were those who had been diagnosed with HTN for at least 6 months and were on treatment for the same. Majority of the participants were diagnosed with HTN 5-10 years ago (32.6\%), and an almost equal number (31.1\%) were diagnosed over 10 years ago. One-fourth the participants were on treatment for $2-5$ years, and a small proportion (10.9\%) were diagnosed recently (that is $<2$ years ago). The time elapsed since diagnosis was found to be positively and mildly associated with age of the participants $(\mathrm{p}<0.001$, Pearson's correlation coefficient $=0.36$ ) (Table 3 and 4).

The participants included in the study were those who had been diagnosed with HTN for at least 6 months and were on treatment for the same. Majority of the participants were diagnosed with HTN 5-10 years ago (32.6\%), and an almost equal number (31.1\%) were diagnosed over 10 years ago. One-fourth the participants were on treatment for

Table 1: Socio-demographic profile of participants $(n=341)$

\begin{tabular}{lll}
\hline Variable & Count & Frequency \% \\
\hline Gender of participant & & \\
$\quad$ Female & 197 & 57.8 \\
$\quad$ Male & 144 & 42.2 \\
Marital status of participant & 6 & 1.8 \\
$\quad$ Single & 291 & 85.3 \\
Married & 44 & 12.9 \\
$\quad$ Widowed & & \\
Religion of participant & 265 & 77.7 \\
Hindu & 25 & 7.3 \\
Muslim & 51 & 15.0 \\
Christian & & \\
Education level of participant & 91 & 26.7 \\
Illiterate & 140 & 41.1 \\
Completed primary school & 70 & 20.5 \\
Completed high school & 40 & 11.7 \\
$\quad$ Completed graduation/postgraduation & & \\
Occupation of participant & 59 & 17.3 \\
$\quad$ Unemployed & 165 & 48.4 \\
Homemaker & 35 & 10.3 \\
Laborer & 58 & 17.0 \\
Self-employed & 24 & 7.0 \\
Service/Professional & & \\
Socio-economic status of participant & 2 & 0.6 \\
$\quad$ Lower-lower class & 67 & 19.6 \\
$\quad$ Upper-lower class & 138 & 40.5 \\
Lower-middle class & 126 & 37.0 \\
Upper-middle class & 8 & 2.3 \\
Upper class & & \\
\hline
\end{tabular}

Table 2: Association between and age and socio-demographic factor in hypertensive patients

\begin{tabular}{|c|c|c|c|}
\hline \multirow[t]{2}{*}{ Socio-demographic variable } & \multicolumn{2}{|c|}{$\begin{array}{l}\text { Age of participant } \\
\text { (in years) }\end{array}$} & \multirow[t]{2}{*}{ p-value } \\
\hline & Mean & $\begin{array}{l}\text { Standard } \\
\text { Deviation }\end{array}$ & \\
\hline \multicolumn{4}{|l|}{ Gender } \\
\hline Female & 62.76 & 10.42 & 0.624 \\
\hline Male & 63.36 & 12.04 & \\
\hline \multicolumn{4}{|l|}{ Marital status } \\
\hline Single & 47.17 & 26.16 & $<0.001$ \\
\hline Married & 62.53 & 10.33 & \\
\hline Widowed & 68.36 & 10.60 & \\
\hline \multicolumn{4}{|l|}{ Religion } \\
\hline Hindu & 63.49 & 10.89 & 0.023 \\
\hline Muslim & 57.16 & 12.56 & \\
\hline Christian & 63.39 & 10.98 & \\
\hline \multicolumn{4}{|l|}{ Education level of participant } \\
\hline Illiterate & 67.10 & 9.21 & $<0.001$ \\
\hline Primary school & 63.95 & 9.85 & \\
\hline Completed high school & 59.16 & 12.88 & \\
\hline graduation/postgraduation & 57.20 & 11.83 & \\
\hline \multicolumn{4}{|l|}{$\begin{array}{l}\text { Socio-economic status of } \\
\text { participant }\end{array}$} \\
\hline Lower-lower class & 42.50 & 14.85 & $<0.025$ \\
\hline Upper-lower class & 62.72 & 9.15 & \\
\hline Lower-middle class & 61.96 & 10.97 & \\
\hline Upper-middle class & 64.40 & 11.92 & \\
\hline Upper class & 66.88 & 9.92 & \\
\hline \multicolumn{4}{|l|}{ Occupation of participant } \\
\hline Unemployed & 70.47 & 11.98 & $<0.001$ \\
\hline Homemaker & 63.04 & 10.03 & \\
\hline Laborer & 58.66 & 10.27 & \\
\hline Self-employed & 57.71 & 9.99 & \\
\hline Service/Professional & 63.71 & 10.17 & \\
\hline
\end{tabular}


2-5 years, and a small proportion (10.9\%) were diagnosed recently (i.e. $<2$ years ago). The time elapsed since diagnosis was found to be positively and mildly associated with age of the participants $(\mathrm{p}<0.001$, Pearson's correlation coefficient $=0.36$ ) (Table 4)

To test patient's knowledge, two questions were asked: One, about the risk factors for HTN, and two, about the complications caused by HTN. Half the patients did not have any idea about the risk factors, and $63.6 \%$ patients did not know about the complications of HTN. Participants' knowledge was associated with their age $(p=0.036$ for risk factors, $p=0.017$ for complications), marital status ( $p=0.001$ for risk factors, $p=0.002$ for complications), and education ( $p=0.001$ for risk factors, $\mathrm{p}<0.001$ for complications). Participants' occupation was associated with knowledge of complications of HTN ( $\mathrm{p}=0.002)$. There was no association between knowledge and gender, religion, socioeconomic status, nor to the time elapsed since diagnosis. Regression analysis (Tables 3 and 4) further revealed that only education level was a definite indicator of knowledge levels, while other factors were confounders. Table 5 describes knowledge of participants, based on their education levels. When asked to self-assess their health, majority said they were in good health $(71 \%)$, while almost one-fourth of the participants were unable to provide an answer and said they were uncertain. When tested against socio-demographic variables (first using ANOVA for individual variables, followed by regression analysis to eliminate confounding variables), it was found that the self-assessment is influenced by education level of participant $(\mathrm{p}=0.003)$ and time elapsed since diagnosis of HTN ( $\mathrm{p}<0.001$ ) (Tables 5.1, 5.2 and 6). Those with lower education or illiterate participants were unable to provide a self-assessment, just as participants who had HTN for than 5 years were unable to.
Education and time elapsed since diagnosis also influenced patients' daily experiences while working. Associations of other variables were found to be insignificant when tested by ANOVA and regression analysis. The higher the education level of the participant, the greater was their disinterest and displeasure experienced while working $(\mathrm{p}<0.001)$. Participants who had been recently diagnosed with HTN, experienced higher levels of disinterest in work as compared to those who had been hypertensive for longer duration $(\mathrm{p}<0.001)$. These factors influenced patients' concentration while working as well. The higher the education, the lower was their lack of concentration $(\mathrm{p}<0.001)$, while as the number of years since diagnosis increased, patients experienced greater lack of concentration $(\mathrm{p}=0.003)$ (Tables 5.1 and 5.2).

Majority (70\%) patients believed that they were experiencing lack of concentration and disinterest in work due to their HTN, while only $18.2 \%$ said this was unrelated to HTN. Participant perception about the cause of their disinterest and lack of concentration was associated with their education $(p=0.003)$ and occupation $(p=0.004)$. Educated people and service professionals were less likely to associate their experiences at work with HTN (Tables 6-8). When asked about their perception about the seriousness of their disease (HTN), most of the patients (57.2\%) believed it was a serious problem and $27 \%$ said it was not serious. The perceived seriousness among illiterates $(75.8 \%)$ was dramatically higher than that of graduates and post-graduates (35\%), and this difference was statistically significant $(\mathrm{p}=0.002)$ (Tables 6-8).

When asked for their perception regarding the medication they take, majority of the patients (88\%) said that it helps stabilize their blood

Table 3: Participants' knowledge based on level of education

\begin{tabular}{|c|c|c|c|c|c|c|c|c|}
\hline \multirow[t]{3}{*}{ Participants' knowledge } & \multicolumn{8}{|c|}{ Education level of participant } \\
\hline & \multicolumn{2}{|c|}{ Illiterate } & \multicolumn{2}{|c|}{$\begin{array}{l}\text { Completed primary } \\
\text { school }\end{array}$} & \multicolumn{2}{|c|}{$\begin{array}{l}\text { Completed high } \\
\text { school }\end{array}$} & \multicolumn{2}{|c|}{$\begin{array}{l}\text { Completed graduation/ } \\
\text { post-graduation }\end{array}$} \\
\hline & Count & Column n \% & Count & Column n \% & Count & Column n \% & Count & Column n \% \\
\hline \multicolumn{9}{|l|}{ Risk factors of hypertension } \\
\hline Stress & 5 & 5.5 & 38 & 27.1 & 20 & 28.6 & 13 & 32.5 \\
\hline Increasing age & 12 & 13.2 & 13 & 9.3 & 4 & 5.7 & 1 & 2.5 \\
\hline Excessive salt consumption & 2 & 2.2 & 7 & 5.0 & 2 & 2.9 & 0 & 0.0 \\
\hline Family history of hypertension & 2 & 2.2 & 1 & 0.7 & 5 & 7.1 & 1 & 2.5 \\
\hline Smoking & 1 & 1.1 & 0 & 0.0 & 0 & 0.0 & 0 & 0.0 \\
\hline All of the above & 1 & 1.1 & 4 & 2.9 & 20 & 28.6 & 18 & 45.0 \\
\hline Don't know & 68 & 74.7 & 77 & 55.0 & 19 & 27.1 & 7 & 17.5 \\
\hline \multicolumn{9}{|c|}{ Complications caused by uncontrolled hypertension } \\
\hline Cardiovascular diseases & 0 & 0.0 & 3 & 2.1 & 1 & 1.4 & 2 & 5.0 \\
\hline Chronic heart disease & 1 & 1.1 & 1 & 0.7 & 1 & 1.4 & 0 & 0.0 \\
\hline Stroke & 6 & 6.6 & 29 & 20.7 & 23 & 32.9 & 7 & 17.5 \\
\hline Don't know & 83 & 91.2 & 95 & 67.9 & 28 & 40.0 & 11 & 27.5 \\
\hline
\end{tabular}

Table 4: Patient self-assessment of their health

\begin{tabular}{|c|c|c|c|c|c|c|c|c|}
\hline \multirow[t]{3}{*}{ Variable } & \multicolumn{8}{|c|}{ Patient self-assessment of their health } \\
\hline & \multicolumn{2}{|l|}{ Poor } & \multicolumn{2}{|l|}{ Good } & \multicolumn{2}{|c|}{ Very good } & \multicolumn{2}{|c|}{$\begin{array}{l}\text { Uncertain/unable to } \\
\text { assess }\end{array}$} \\
\hline & Count & Column n \% & Count & Column n \% & Count & Column n \% & Count & Column n \% \\
\hline \multicolumn{9}{|l|}{ Education level } \\
\hline Illiterate & 4 & 50.0 & 54 & 22.3 & 2 & 28.6 & 31 & 36.9 \\
\hline Completed primary school & 3 & 37.5 & 93 & 38.4 & 2 & 28.6 & 42 & 50.0 \\
\hline Completed high school & 1 & 12.5 & 60 & 24.8 & 1 & 14.3 & 8 & 9.5 \\
\hline Completed graduation/postgraduation & 0 & 0.0 & 35 & 14.5 & 2 & 28.6 & 3 & 3.6 \\
\hline \multicolumn{9}{|l|}{ Time elapsed since diagnosis of hypertension } \\
\hline 6 months-2 years & 0 & 0.0 & 33 & 13.6 & 1 & 14.3 & 3 & 3.6 \\
\hline 2 years -5 years & 2 & 25.0 & 72 & 29.8 & 3 & 42.9 & 10 & 11.9 \\
\hline 5 years -10 years & 1 & 12.5 & 84 & 34.7 & 1 & 14.3 & 25 & 29.8 \\
\hline More than 10 years & 5 & 62.5 & 53 & 21.9 & 2 & 28.6 & 46 & 54.8 \\
\hline
\end{tabular}


Table 5.1: Patient experiences and associated factors

\begin{tabular}{|c|c|c|c|c|c|c|c|c|}
\hline \multirow[t]{3}{*}{ Variable } & \multicolumn{8}{|c|}{ Patient experiences and associated factors } \\
\hline & \multicolumn{2}{|l|}{ None } & \multicolumn{2}{|c|}{$\begin{array}{l}\text { Low/disinterested } \\
\text { on several days }\end{array}$} & \multicolumn{2}{|c|}{$\begin{array}{l}\text { Moderate/disinterested } \\
\text { on most days }\end{array}$} & \multicolumn{2}{|c|}{$\begin{array}{l}\text { High/always } \\
\text { disinterested }\end{array}$} \\
\hline & Count & Row n\% & Count & Row n\% & Count & Row n\% & Count & Row n\% \\
\hline \multicolumn{9}{|l|}{ Education level of participant } \\
\hline Illiterate & 9 & 9.9 & 16 & 17.6 & 19 & 20.9 & 47 & 51.6 \\
\hline Completed primary school & 6 & 4.3 & 35 & 25.0 & 16 & 11.4 & 83 & 59.3 \\
\hline Completed graduation/postgraduation & 1 & 2.5 & 3 & 7.5 & 1 & 2.5 & 35 & 87.5 \\
\hline \multicolumn{9}{|l|}{ Time elapsed since diagnosis of hypertension } \\
\hline 6 months -2 years & 1 & 2.7 & 3 & 8.1 & 1 & 2.7 & 32 & 86.5 \\
\hline 2 years -5 years & 5 & 5.7 & 12 & 13.8 & 8 & 9.2 & 62 & 71.3 \\
\hline 5 years -10 years & 2 & 1.8 & 22 & 19.8 & 13 & 11.7 & 74 & 66.7 \\
\hline More than 10 years & 11 & 10.4 & 27 & 25.5 & 20 & 18.9 & 48 & 45.3 \\
\hline
\end{tabular}

Table 5.2: Patient experiences and associated factors

\begin{tabular}{|c|c|c|c|c|c|c|c|c|}
\hline \multirow[t]{3}{*}{ Variable } & \multicolumn{8}{|c|}{ Level of lack of concentration experienced by participant while working } \\
\hline & \multicolumn{2}{|l|}{ None } & \multicolumn{2}{|c|}{$\begin{array}{l}\text { Low/unable to } \\
\text { concentrate on } \\
\text { several days }\end{array}$} & \multicolumn{2}{|c|}{$\begin{array}{l}\text { Moderate/unable } \\
\text { to concentrate on } \\
\text { most days }\end{array}$} & \multicolumn{2}{|c|}{$\begin{array}{l}\text { High/always } \\
\text { unable to } \\
\text { concentrate }\end{array}$} \\
\hline & Count & Row n \% & Count & Row n \% & Count & Row n \% & Count & Row n \% \\
\hline \multicolumn{9}{|l|}{ Education level of participant } \\
\hline Illiterate & 21 & 23.1 & 25 & 27.5 & 25 & 27.5 & 20 & 22.0 \\
\hline Completed primary school & 42 & 30.0 & 41 & 29.3 & 30 & 21.4 & 27 & 19.3 \\
\hline Completed high school & 38 & 54.3 & 11 & 15.7 & 10 & 14.3 & 11 & 15.7 \\
\hline Completed graduation/postgraduation & 27 & 67.5 & 2 & 5.0 & 8 & 20.0 & 3 & 7.5 \\
\hline \multicolumn{9}{|l|}{ Time elapsed since diagnosis of hypertension } \\
\hline 6 months-2 years & 23 & 62.2 & 6 & 16.2 & 2 & 5.4 & 6 & 16.2 \\
\hline 2 years -5 years & 36 & 41.4 & 17 & 19.5 & 23 & 26.4 & 11 & 12.6 \\
\hline 5 years -10 years & 37 & 33.3 & 31 & 27.9 & 23 & 20.7 & 20 & 18.0 \\
\hline More than 10 years & 32 & 30.2 & 25 & 23.6 & 25 & 23.6 & 24 & 22.6 \\
\hline
\end{tabular}

Table 6: Participant perception and associated factors

\begin{tabular}{|c|c|c|c|c|c|c|}
\hline \multirow[t]{3}{*}{ Variable } & \multicolumn{6}{|c|}{ Participant's perception about cause of disinterest and lack of concentration } \\
\hline & \multicolumn{2}{|c|}{ Due to hypertension } & \multicolumn{2}{|c|}{$\begin{array}{l}\text { Other reason, not related to } \\
\text { hypertension }\end{array}$} & \multicolumn{2}{|c|}{ Uncertain/don't know } \\
\hline & Count & Row n \% & Count & Row n \% & Count & Row n \% \\
\hline \multicolumn{7}{|l|}{ Education level of participant } \\
\hline Illiterate & 75 & 82.4 & 8 & 8.8 & 8 & 8.8 \\
\hline Completed primary school & 107 & 76.4 & 20 & 14.3 & 13 & 9.3 \\
\hline Completed high school & 37 & 52.9 & 20 & 28.6 & 13 & 18.6 \\
\hline Completed graduation/post-graduation & 18 & 45.0 & 14 & 35.0 & 8 & 20.0 \\
\hline \multicolumn{7}{|l|}{ Occupation of participant } \\
\hline Unemployed & 46 & 78.0 & 8 & 13.6 & 5 & 8.5 \\
\hline Homemaker & 124 & 75.2 & 29 & 17.6 & 12 & 7.3 \\
\hline Laborer & 22 & 62.9 & 6 & 17.1 & 7 & 20.0 \\
\hline Self-employed & 40 & 69.0 & 7 & 12.1 & 11 & 19.0 \\
\hline Service/Professional & 5 & 20.8 & 12 & 50.0 & 7 & 29.2 \\
\hline
\end{tabular}

Table 7: Patient's perception about medication

\begin{tabular}{lll}
\hline Perception & Count (n=341) & Frequency (\%) \\
\hline They do not stabilize BP & 27 & 7.9 \\
$\begin{array}{l}\text { They stabilize BP and help treat } \\
\text { hypertension }\end{array}$ & 273 & 80.1 \\
Uncertain & 41 & 12.0 \\
\hline
\end{tabular}

pressure and control HTN. This perception was not associated with any socio-demographic variable Table 8 . Almost half the patients interviewed believed that lifestyle modification helps control HTN, $44 \%$ were unsure about the role, and only $5 \%$ said that lifestyle modification does not help control HTN. This perception was found to be associated with time elapsed since diagnosis $(p=0.001)$ (Tables 7-9). 
Patient's feelings about their diagnosis were recorded, and majority $(43.7 \%)$ were worried because of their HTN. These feelings of worry were influenced by education level of participant $(p=0.001)$ and their socio-economic status $(\mathrm{p}=0.034)$. Participants' feelings about the prognosis of their disease was influenced by gender $(\mathrm{p}=0.003)$ and socio-economic status $(p=0.012)$ (Tables 9-12). None of the patients felt that HTN cannot be cured.

Three hundred and twenty-three (94.7\%) participants told that they were getting enough support from the health care providers. Two hundred and eighty-two (82.7\%) participants told that their physician strictly advised to take medication. According to this study, it shows that only $7(2.1 \%)$ were not advised to follow lifestyle modifications by the health-care providers. Three hundred and thirty-four (97.9\%) respondents said that physician is friendly with them while treating. And 327 (95.9\%) people told physician treats them with respect. Two hundred and sixty-one (76.5) participants said that health-care providers other than physician always treat them with respect, but only once said that they never treat with respect (Table 11).

Almost half of the participants, that is, $186(54.5 \%)$ travel 3 to $5 \mathrm{~km}$ to reach the health-care facility and $38(11.1 \%)$ participants need to travel $1-3 \mathrm{~km}$. Sixty-four (18.8\%) and $53(15.5 \%)$ respondents needs to travel 5-10 km and more than $10 \mathrm{~km}$, respectively (Tables 12 and 13). Very small participants, that is, $6.5 \%$ (22) were smokers and did not adhere to lifestyle modification advice they received in regards to smoking. Only one participant told that he smokes more than 1 packet of cigarettes daily. Maximum, that is, $81.8 \%$ (18) participants told that they smoke less than half packet of cigarettes per day. About 40.9\% (9) participants were aware of consequences of smoking. Nineteen (86.4\%) participants told that they were advised to quit smoking by physician but $45.5 \%$ (10) smokers tried to quit smoking (Tables 14 and 15).

Almost two-third of the patient (61.9\%) count-211 told that they exercise. However, out of this only $70 \%$ participants exercise daily. Approximately half the numbers of all participants are non-adherent to the lifestyle modifications advised in regards to exercise. Around 91\% (192) participants exercise for $<1 / 2 \mathrm{~h}$. Only $6(2.8 \%)$ participant practiced Yoga while all the remaining participants went walking as a form of exercise. Majority, 295 (86.5\%) were advised by their physician to exercise and explained the importance of exercise in HTN (Tables 16 and 17)

Adherence to exercise is seen in the age group of 34-48 years and 4963 years, that is, $70.4 \%$ (19) and $74.6 \%$ (100), respectively, ( $\mathrm{p}=0.001)$. Higher the education level better adherence to exercise $(\mathrm{p}=0.001)$ was seen. Majority (92.5\%) graduates and $84.3 \%$ of high school passed participants had good adherence to exercise. Professionals had good adherence in regards to exercise $91.7 \%$ (22) which was followed by participants with own business $75.9 \%$ (44). Hundred and three (81.7\%) participants from the upper middle class have the high adherence to exercise (Table 18).

Participants with awareness regarding risk factors of HTN had good adherence to exercise, that is, $40(93.0 \%)$. Patient with awareness

Table 8: Patient's perception about lifestyle modification, categorized by time elapsed since diagnosis

\begin{tabular}{|c|c|c|c|c|c|c|c|c|}
\hline \multirow[t]{2}{*}{ Perception } & \multicolumn{2}{|c|}{6 months-2 years } & \multicolumn{2}{|c|}{2 years- 5 years } & \multicolumn{2}{|c|}{5 years- 10 years } & \multicolumn{2}{|c|}{ More than 10 years } \\
\hline & Count & Column \% & Count & Column \% & Count & Column \% & Count & Column \% \\
\hline Helps control hypertension & 23 & $62.2 \%$ & 54 & $62.1 \%$ & 52 & $46.8 \%$ & 45 & $42.5 \%$ \\
\hline Does not help control hypertension & 2 & $5.4 \%$ & 5 & $5.7 \%$ & 5 & $4.5 \%$ & 5 & $4.7 \%$ \\
\hline Uncertain & 12 & $32.4 \%$ & 28 & $32.2 \%$ & 54 & $48.6 \%$ & 56 & $52.8 \%$ \\
\hline
\end{tabular}

Table 9: Patient's feelings on diagnosis and associated factors

\begin{tabular}{|c|c|c|c|c|c|c|}
\hline \multirow[t]{2}{*}{ Associated variables } & \multicolumn{2}{|c|}{$\begin{array}{l}\text { Worried because of } \\
\text { hypertension }\end{array}$} & \multicolumn{2}{|c|}{$\begin{array}{l}\text { Not worried by } \\
\text { hypertension }\end{array}$} & \multicolumn{2}{|c|}{ Uncertain } \\
\hline & Count & Row n \% & Count & Row n \% & Count & Row n \% \\
\hline \multicolumn{7}{|l|}{ Education level of participant } \\
\hline Illiterate & 56 & 61.5 & 15 & 16.5 & 20 & 22.0 \\
\hline Completed primary school & 65 & 46.4 & 36 & 25.7 & 39 & 27.9 \\
\hline Completed high school & 17 & 24.3 & 30 & 42.9 & 23 & 32.9 \\
\hline \multicolumn{7}{|l|}{ Socio-economic status of participant } \\
\hline Lower-lower class & 0 & 0.0 & 1 & 50.0 & 1 & 50.0 \\
\hline Upper-lower class & 34 & 50.7 & 14 & 20.9 & 19 & 28.4 \\
\hline Lower-middle class & 59 & 42.8 & 38 & 27.5 & 41 & 29.7 \\
\hline Upper-middle class & 53 & 42.1 & 47 & 37.3 & 26 & 20.6 \\
\hline Upper class & 3 & 37.5 & 2 & 25.0 & 3 & 37.5 \\
\hline
\end{tabular}

Table 10: Patient's feelings: On prognosis and associated variables

\begin{tabular}{|c|c|c|c|c|c|c|}
\hline \multirow[t]{2}{*}{ Socio-demographic variable } & \multicolumn{2}{|c|}{$\begin{array}{l}\text { Hypertension cannot be } \\
\text { cured }\end{array}$} & \multicolumn{2}{|c|}{$\begin{array}{l}\text { Hypertension can be } \\
\text { cured }\end{array}$} & \multicolumn{2}{|c|}{ Uncertain } \\
\hline & Count & Column \% & Count & Column \% & Count & Column \% \\
\hline \multicolumn{7}{|l|}{ Gender of participant } \\
\hline Female & 0 & 0.0 & 55 & 48.7 & 119 & 63.3 \\
\hline Male & 0 & 0.0 & 58 & 51.3 & 69 & 36.7 \\
\hline \multicolumn{7}{|c|}{ Socio-economic status of participant } \\
\hline Lower-lower class & 0 & 0.0 & 0 & 0.0 & 2 & 1.1 \\
\hline Upper-lower class & 0 & 0.0 & 16 & 14.2 & 39 & 20.7 \\
\hline Lower-middle class & 0 & 0.0 & 43 & 38.1 & 80 & 42.6 \\
\hline Upper-middle class & 0 & 0.0 & 51 & 45.1 & 64 & 34.0 \\
\hline Upper class & 0 & 0.0 & 3 & 2.7 & 3 & 1.6 \\
\hline
\end{tabular}


Table 11: Health care support

\begin{tabular}{|c|c|c|c|c|c|c|}
\hline \multirow{2}{*}{$\begin{array}{l}\text { Variable } \\
\text { All the health workers } \\
\text { other than physician n } \\
\text { treat with respect }\end{array}$} & \multicolumn{2}{|c|}{ Always } & \multicolumn{2}{|c|}{ Sometimes } & \multicolumn{2}{|c|}{ Never } \\
\hline & 323 & $94.7 \%$ & 18 & $5.3 \%$ & & \\
\hline $\begin{array}{l}\text { Advice to take medicine } \\
\text { strictly by physician }\end{array}$ & 282 & $82.7 \%$ & 59 & $17.3 \%$ & & \\
\hline $\begin{array}{l}\text { Advice to follow lifestyle } \\
\text { modification by health } \\
\text { care providers }\end{array}$ & 334 & $97.9 \%$ & 7 & $2.1 \%$ & & \\
\hline Physician is friendly & 334 & $97.9 \%$ & 7 & $2.1 \%$ & & \\
\hline $\begin{array}{l}\text { Physician treats with } \\
\text { respect }\end{array}$ & 327 & $95.9 \%$ & 14 & $4.1 \%$ & & \\
\hline $\begin{array}{l}\text { Health care workers } \\
\text { treats you with respect }\end{array}$ & 261 & $76.5 \%$ & 79 & $23.2 \%$ & 1 & $0.3 \%$ \\
\hline
\end{tabular}

Table 12: Distance to travel to health-care center

\begin{tabular}{lll}
\hline Variables & Frequency & Percentage \\
\cline { 1 - 1 } Kilometers range & & \\
\hline $1-3 \mathrm{~km}$ & 38 & 11.1 \\
$3-5 \mathrm{~km}$ & 186 & 54.5 \\
$5-10 \mathrm{~km}$ & 64 & 18.8 \\
More than 10 & 53 & 15.5 \\
Total & 341 & 100.0 \\
\hline
\end{tabular}

Table 13: Frequency of alcohol consumption

\begin{tabular}{lll}
\hline Alcohol variable & Frequency & Percentage \\
\hline Use of alcohol & & \\
Yes & 82 & 24.0 \\
No & 259 & 76.0 \\
& 16 & 19.5 \\
Drinking frequency & & \\
Weekly once & 23 & 28.0 \\
Occasionally & 43 & 52.5 \\
Quantity consumed & & \\
60 ml & 4 & 4.9 \\
90 ml & 50 & 61.0 \\
180 ml & 28 & 34.1 \\
Awareness of consequences on hypertension & \\
Yes & 21 & 25.6 \\
No & 61 & 74.4 \\
Physician advice to quit alcohol & & \\
Yes & 42 & 51.2 \\
No & 40 & \\
Tried to quit & & 88.8 \\
Yes & 11 & \\
No & 71 & \\
\hline
\end{tabular}

regarding the complications caused by the uncontrolled HTN also adhered to lifestyle modification in terms of exercise $(p=0.001)$. Majority, 96\% (48), of respondent adhered to exercise. The participants who perceived their own health as good and very good had better adherence to exercise $(p=0.001)$. The patients, who adhered to exercise, also consumed less quantity of salt (Table 19). Many patients who are smokers are also alcoholic $(\mathrm{p}=0.001)$. Alcoholic participants mostly followed a mixed diet $(\mathrm{p}=0.001)$ (Table 20)

\section{DISCUSSION}

The current study was undertaken in three secondary care hospitals of Udupi district among hypertensive patients to study the level of awareness, knowledge regarding HTN, and adherence to lifestyle modification. A standardized questionnaire was used which included socio-demographic factors, knowledge, perception, and lifestyle
Table 14: Smoking status and awareness

\begin{tabular}{lll}
\hline Variables & Frequency & Percentage \\
\hline Smoking status & & \\
$\quad$ Yes & 22 & 6.5 \\
No & 319 & 93.5 \\
Cigarette consumption per day & & \\
1-3 cigarettes & 7 & 31.8 \\
$\quad$ <half pack & 11 & 50.0 \\
Up to 1 pack & 3 & 13.6 \\
>1 pack & 1 & 4.5 \\
Physician advice on the consequences & & \\
Yes & 19 & 86.4 \\
No & 3 & 13.6 \\
Tried to quit smoking & & \\
$\quad$ Yes & 10 & 45.5 \\
No & 12 & 54.5 \\
Awareness on the consequences & & \\
Yes & 9 & 40.9 \\
No & 13 & 59.1 \\
\hline
\end{tabular}

Table 15: Awareness on dietary habits on hypertension

\begin{tabular}{lll}
\hline Variables & Frequency & Percentage \\
\hline Type of diet & & \\
$\quad$ Mixed & 46 & 13.5 \\
$\quad$ Vegetarian & 295 & 86.5 \\
Knows that salt intake increases blood & & \\
pressure & & \\
$\quad$ Yes & 302 & 88.6 \\
$\quad$ No & 39 & 11.4 \\
Physician advice to take less salt & & \\
$\quad$ Yes & 309 & 90.6 \\
$\quad$ No & 32 & 9.4 \\
Quantity of salt intake & & \\
$\quad$ Less & 133 & 39 \\
$\quad$ Moderate to excess & 208 & 61 \\
Eats more sweet food & & \\
$\quad$ Yes & 57 & 16.7 \\
$\quad$ No & 284 & 83.3 \\
Eats more fatty food & & \\
$\quad$ Yes & 65 & 19.1 \\
$\quad$ No & 276 & 80.9 \\
\hline
\end{tabular}

Table 16: Exercise pattern

\begin{tabular}{lll}
\hline Variables & Frequency & Percentage \\
\hline Exercise & & \\
$\quad$ Yes & 211 & 61.9 \\
$\quad$ No & 130 & 38.1 \\
Exercise pattern & & \\
$\quad$ Daily & 148 & 70.1 \\
$\quad$ Occasionally & 63 & 29.9 \\
Duration of exercise & & \\
$\quad<30$ min & 101 & 47.9 \\
1/2-1 h & 91 & 43.1 \\
1-2 h & 18 & 8.5 \\
$\quad>3$ h & 1 & 0.5 \\
Type of exercise & & \\
Yoga & 6 & 2.8 \\
Walking/jogging & 205 & 97.2 \\
Physician advise to exercise & & \\
Yes & 295 & 86.5 \\
$\quad$ No & 46 & 13.5 \\
Physician advise Importance of exercising & & \\
$\quad$ Yes & 201 & 95.3 \\
No & 10 & 4.7 \\
\hline
\end{tabular}

modifications. The level of knowledge and perception regarding the health is analyzed. The prevalence of adherence and non-adherence to 
lifestyle modification advised in HTN is found separately for each factor such as smoking, alcohol, diet, salt intake, and exercise.

Single people develop HTN at a much younger age than married people do $(\mathrm{p}<0.001)$ and it may be because of low social support and stress [11]. According to study conducted by Lipowicz et al., single men's systolic blood pressure and diastolic blood pressure were higher than married men. Single men were at higher risk of HTN in comparison to married. The difference between married and single was chronic stress, low community support, and food habits such as potassium

Table 17: Frequencies of lifestyle modifications

\begin{tabular}{lll}
\hline Variables & Frequency & Percentage (\%) \\
\hline Smoking & & \\
Yes & 22 & 6.5 \\
No & 319 & 93.5 \\
Alcohol & & \\
$\quad$ Yes & 82 & 24 \\
No & 259 & 76 \\
Diet & & \\
Mixed & 295 & 86.5 \\
$\quad$ Vegetarian & 46 & 13.5 \\
Salt intake & & \\
Less & 133 & 39 \\
$\quad$ Moderate to excess & 208 & 61 \\
Exercise & & \\
$\quad$ Yes & 211 & 62 \\
No & 130 & 38 \\
\hline
\end{tabular}

and sodium consumption, and loneliness, these above factors can be considered as factors [12,13]. There was an association between age and religion, which showed that Hindus and Christians develop HTN at a later age, when compared with Muslims $(p=0.023)$. This may be because of high red meat intake [14].

The more educated a person is, the earlier in life he/she develops HTN $(p<0.001)$. Either this could be due to lifestyle choices of educated people, or it could also indicate an under-diagnosis of HTN in lesser/uneducated people due to lack of awareness. According to study conducted by Rakesh Ranjan et al., there was difference which is significant was seen in the prevalence of high blood pressure with respect to educational level [15]. In the present study, the prevalence of HTN was comparatively much lower among those who were educated up to graduation and above. According to Wang et al., patients who are educated may be more aware about the disease condition and preventive methods. These may be the reasons for the above said variation [16].

The participants included in the study were those who had been diagnosed with HTN for at least 6 months and were on treatment for the same. Majority of the participants were diagnosed with HTN 5-10 years ago (32.6\%), and an almost equal number (31.1\%) were diagnosed over 10 years ago. The time elapsed since diagnosis was found to be positively and mildly associated with age of the participants $(\mathrm{p}<0.001$, Pearson's correlation coefficient=0.36). According to Pinto et al., the risk of having high blood pressure increases with age of participants [17]. Occurrence of HTN increased by age ranging from

Table 18: Association between exercise and socio demographic factors

\begin{tabular}{|c|c|c|c|c|c|}
\hline \multirow[t]{3}{*}{ Socio-demographic factors } & \multicolumn{4}{|l|}{ Exercise } & \multirow[t]{3}{*}{ p-value } \\
\hline & \multicolumn{2}{|l|}{ Yes } & \multicolumn{2}{|l|}{ No } & \\
\hline & Frequency & Row n\% & Frequency & Row n \% & \\
\hline \multicolumn{6}{|l|}{ Age (years) } \\
\hline $18-33$ & 4 & 66.7 & 2 & 33.3 & 0.001 \\
\hline $38-48$ & 19 & 70.4 & 8 & 29.6 & \\
\hline $49-63$ & 100 & 74.6 & 34 & 25.4 & \\
\hline $79-93$ & 9 & 52.9 & 8 & 47.1 & \\
\hline \multicolumn{6}{|l|}{ Education } \\
\hline Graduates or post graduate & 37 & 92.5 & 3 & 7.5 & 0.001 \\
\hline High school & 59 & 84.3 & 11 & 15.7 & \\
\hline Illiterate & 81 & 37.4 & 59 & 62.6 & \\
\hline Primary school & 34 & 57.9 & 57 & 42.1 & \\
\hline \multicolumn{6}{|l|}{ Occupation } \\
\hline House wife & 101 & 61.2 & 64 & 38.8 & 0.001 \\
\hline Own business & 44 & 75.9 & 14 & 24.1 & \\
\hline Professional & 22 & 91.7 & 2 & 8.3 & \\
\hline Unemployed & 27 & 45.8 & 32 & 54.2 & \\
\hline \multicolumn{6}{|l|}{ Socio-economic status } \\
\hline Upper class & 4 & 50.5 & 4 & 50.0 & 0.001 \\
\hline Upper middle class & 103 & 81.7 & 23 & 18.3 & \\
\hline Lower middle class & 77 & 55.8 & 61 & 44.2 & \\
\hline Upper lower class & 26 & 38.8 & 41 & 61.2 & \\
\hline Lower class & 1 & 50.0 & 1 & 50.0 & \\
\hline
\end{tabular}

Table 19: Salt intake and hypertension

\begin{tabular}{|c|c|c|c|c|c|}
\hline \multirow[t]{2}{*}{ SAL intake } & \multicolumn{2}{|c|}{ Less quantity } & \multicolumn{2}{|c|}{ Moderate to excess quantity } & \multirow[t]{2}{*}{ p-value } \\
\hline & Frequency & Row n\% & Frequency & Row n\% & \\
\hline \multicolumn{6}{|c|}{ Hypertension diagnosed } \\
\hline $2-5$ years & 44 & 50.6 & 43 & 49.4 & 0.001 \\
\hline $5-10$ years & 47 & 42.3 & 64 & 57.7 & \\
\hline 6 months- 2 years & 13 & 35.1 & 24 & 64.9 & \\
\hline >10 years & 29 & 27.4 & 77 & 72.6 & \\
\hline
\end{tabular}


Table 20: Association between alcohol with smoking and diet

\begin{tabular}{cllllll}
\hline \multirow{2}{*}{ Alcohol } & \multicolumn{2}{l}{ Yes } & & & No & \multirow{2}{*}{ p-value } \\
\cline { 2 - 3 } & Frequency & Row N\% & & Frequency & Row N\% & \\
\hline Smoking & & & & & \\
Yes & 15 & 18.3 & & 67 & 81.7 & 0.001 \\
$\quad$ No & 7 & 2.7 & 252 & 97.3 & \\
Diet & & & & & \\
Yes & 82 & 27.8 & & 213 & 72.2 & \\
No & 0 & 0.0 & & 46 & 10.05 & \\
\hline
\end{tabular}

$5.4 \%$ in below 20 years age group to $80 \%$ in $\geq 70$ years age group seen in the study conducted by Ulasi et al. [18].

To test patient's knowledge, risk factors of HTN and complications of HTN were asked. Half the patients did not have any idea about the risk factors, and $63.6 \%$ patients did not know about the complications of HTN. The awareness level seen less in other studies compared to this study. In study conducted by Carroll et al., patients with stroke or transient ischemic attack, $43 \%$ of the high blood pressure participants had awareness regarding risk factors. Samsa et al., in his study interviewed 1261particiipants with increased risk of stroke, in that $41 \%$ of participants were aware of risk factors [19].

Eighty-two $(24.0 \%)$ were alcoholic and are considered in the group of participants that do not adhere to the lifestyle modification advice given to them. Study conducted by Tibue et al., $23.8 \%$ of the study population were alcoholic and $74.8 \%$ of the participants were adherent to lifestyle modification in regard to alcohol intake [20]. Out of them 52.5\% (43) were occasional drinkers and 19.5\% (16) of alcoholic participants are drinking alcohol dally. Fifty (61.0\%) were taking $90 \mathrm{ml}$ of alcohol and 28 (34.1\%) were drinking $180 \mathrm{ml}$ alcohol per sitting. Maximum number of alcoholic participants had no awareness regarding consequences caused by the alcohol in HTN. Half of the participants were not advised to quit alcohol by their physician. In the study of Tibeu et al., 56.9\% the patients were given advice to quit consumption of alcohol by the physician and patients relatives [21]. Only 11 (13.4\%) participants tried to quit drinking in this current study.

Very small number of participants, that is., $6.5 \%$ was smokers and did not adhere to lifestyle modification advice they received in regards to smoking. In the study conducted by Tibeu et al., $14.1 \%$ of participants were smokers. About $40.9 \%$ participants were aware of consequences of smoking. Nineteen (86.4\%) participants told that they were advised to quit smoking by physician but $45.5 \%$ smokers tried to quit smoking. According to Tibeu et al., 57 (41\%) participants were still smoking and $26(45.6 \%)$ participants did even tried to stop smoking [22].

Maximum number of participants, that is, 295 (86.5\%) was practicing mixed diet pattern and only $13.5 \%$ were vegetarian. The prescribed diet in HTN is DASH diet. Red meat, diet with high cholesterol, and salts are restricted in HTN. The DASH diet contains vegetables, fruits, and low fat milk products, which included grains, fish, and nuts with reduced red meat, fat, and sweets helped in controlling high blood pressure in $70 \%$ of patients according to study conducted by Conlin et al. In this current study, maximum participants are practicing mixed diet pattern which included non-vegetarian diet, which may had adverse effect on control of HTN $[23,24]$.

Three hundred and two (88.6\%) patients had awareness that more salt intake will increase blood pressure. In the study conducted by Mochizuki et al., $80.9 \%$ of the participants aware that salt intake has adverse effect on HTN control [25]. Three hundred and nine (90.6\%) participants told that they were advised by the physician to take less salt. Only 39\% (133) patients had reduced their salt intake and thus were adherent to lifestyle modification in regard to salt intake. A large proportion of patients (284 in number $-83.3 \%$ ) told that they eat lesser sweet now than before, it may be because HTN associated with co- morbidities like diabetes and $80.9 \%$ said that they have reduced the consumption of fatty food [26].

Almost two-third of the patient (61.9\%) count-211 told that they exercise. However, out of this only $70 \%$ participants exercise daily. Around $91 \%$ participants exercise for $<1 / 2 \mathrm{~h}$ [27]. Only six $(2.8 \%)$ participant practiced Yoga while all the remaining participants went walking as a form of exercise. In the study conducted by the Tibeu et al. adherence to exercise seen in $65.1 \%$ of the participants, in these, maximum people $(90.1 \%)$ do exercise at least weekly 3 times. Almost same number of respondents does the exercise atheist for $30 \mathrm{~min}$ [27]. The most common type of exercise performed was walking (55.3\%), followed by jogging (28.4\%) and aerobics (16.3\%). More than half of participants (193-56.5\%) participants are non-adherent to the lifestyle modifications in regard to exercise in this current study. In the study conducted by Tibeu et al., adherence exercise was 31.4\%. Majority, $295(86.5 \%)$ were advised by their physician to exercise and explained the importance of exercise in HTN [28]. According to the study conducted by Alsairafi et al., participants who are not doing exercise had uncontrolled high blood pressure compared to the one-fourth of who are practicing [29].

Adherence to exercise is seen in the age group of 34-48 years and 49-63 years, that is, $70.4 \%$ and $74.6 \%$, respectively, $(p=0.001)$. Higher the education level better adherence to exercise $(\mathrm{p}=0.001)$ was seen. Majority (92.5\%) graduates and $84.3 \%$ of high school passed participants had good adherence to exercise. Professionals had good adherence in regard to exercise $91.7 \%$ which was followed by participants with own business $75.9 \%$. Hundred and three $(81.7 \%)$ participants from the upper middle class have the high adherence to exercise $[30,31]$

The study had limitations like the questionnaire would have included about co-morbidities of the participants by which the confounding factor would have been reduced.

\section{CONCLUSION}

The study conducted in secondary care hospitals of Udupi district to know the adherence to life style modification in hypertensive patients visiting medicine OPD. The study found that adherence to exercise, less salt intake, alcohol, and smoking was $43.5 \%, 39.0 \%$, $76.0 \%$, and $93.5 \%$, respectively. There was very less adherence seen in less salt intake and exercise. Adherence to smoking and alcohol was seen comparatively less in this study. The education level and occupation of the participant are associated with the awareness regarding HTN. Education level, occupation, duration of the disease, and awareness regarding risks and complications of HTN are significantly associated with adherence to lifestyle modification. It was found that there was less knowledge about risks and complications of HTN. There was less awareness regarding importance of lifestyle modification in management of HTN. Very low adherence is seen to the advised lifestyle modification in the study population Education regarding the risks and complications of HTN was very low among the participants which also associated with the adherence to lifestyle modifications. Hence, awareness regarding the HTN should be created. Physicians should spend more time in explaining the recommended lifestyle modifications to patients in detail. Each lifestyle modifications should be explained with its importance in control of disease.

\section{ACKNOWLEDGMENT}

Nil.

\section{AUTHOR CONTRIBUTION}

Our sincere thanks to karthik rao in correcting the draft and also to everyone instrumental in collection of results and analysis. 


\section{CONFLICT OF INTEREST}

Nil.

FUNDING

Nil.

\section{REFERENCES}

1. Narkiewicz K. Obesity and hypertension the issue is more complex than we thought. Nephrol Dial Transplant 2006;21:264-7.

2. Mittal BV, Singh AK. Hypertension in the developing world: Challenges and opportunities. Am J Kidney Dis 2010;55:590-8.

3. Kearney PM, Whelton M, Reynolds K, Muntner P, Whelton PK, He J. Global burden of hypertension: Analysis of worldwide data. Lancet 2005;365:217-23.

4. Cornélissen G, Delcourt A, Toussaint G, Otsuka K, Watanabe Y, Siegelová J, et al. Opportunity of detecting pre-hypertension: worldwide data on blood pressure overswinging. Biomed Pharmacother 2005;59:S152-7.

5. Ford CD, Kim MJ, Dancy BL. Perceptions of hypertension and contributing personal and environmental factors among rural Southern African American women. Ethn Dis 2009;19:407.

6. Suter PM, Sierro C, Vetter W. Nutritional factors in the control of blood pressure and hypertension. Nutr Clin Care 2002;5:9-19.

7. Appel LJ, Champagne CM, Harsha DW, Cooper LS, Obarzanek E, Elmer PJ, et al. Effects of comprehensive lifestyle modification on blood pressure control: Main results of the PREMIER clinical trial. JAMA 2003;289:2083-93

8. Ghezelbash S, Ghorbani A. Lifestyle modification and hypertension prevention. ARYA Atherosclerosis 2012;8:202-7.

9. He J, Bazzano LA. Effects of lifestyle modification on treatment and prevention of hypertension. Curr Opin Nephrol Hypertens 2000;9:267-71.

10. O'Brien E, Coats A, Owens P, Petrie J, Padfield PL, Littler WA, et al. Use and interpretation of ambulatory blood pressure monitoring: Recommendations of the British hypertension society. BMJ 2000;320:1128-34

11. Steptoe A, Owen N, Kunz-Ebrecht SR, Brydon L. Loneliness and neuroendocrine, cardiovascular, and inflammatory stress responses in middle-aged men and women. Psychoneuroendocrinology 2004;29:593-611.

12. Arganini C, Saba A, Comitato R, Virgili F, Turrini A. Gender Differences in Food Choice and Dietary Intake in Modern Western Societies. Vol. 4. Public Health-Social and Behavioral Health; 2012. p. 83-102.

13. Dressler WW, Bindon JR. The health consequences of cultural consonance: Cultural dimensions of lifestyle, social support, and arterial blood pressure in an African American community. Am Anthropol 2000;102:244-60.

14. Khan ZH, Minagar M, Dehghan-Tezerjani M. Activation of the reninangiotensin system could cause hypertension during fasting in the Muslims month of Ramadhan. Curr Hypertens Rev 2019;15:2174

15. Ranjan R, Ahmad S, Shukla M, Soni S. An epidemiological study of hypertension in a rural population of Barabanki, Uttar Pradesh. J Community Health Manag 2017;4:5-10.
16. Wang C, Lang J, Xuan L, Li X, Zhang L. The effect of health literacy and self-management efficacy on the health-related quality of life of hypertensive patients in a western rural area of China: A cross-sectional study. Int J Equity Health 2017;16:1-11.

17. Pinto E. Blood pressure and ageing. Postgr Med J 2007;83:109-14.

18. Ulasi II, Ijoma CK, Onwubere BJ, Arodiwe E, Onodugo O, Okafor C. High prevalence and low awareness of hypertension in a market population in Enugu, Nigeria. Int J Hypertens 2011;2011:869675.

19. Harwell TS, Blades LL, Oser CS, Dietrich DW, Okon NJ, Rodriguez DV, et al. Perceived risk for developing stroke among older adults. Prev Med 2005;41:791-4

20. Campbell N, Burgess E, Choi B, Taylor G, Wilson E, Cléroux J, et al. Lifestyle modifications to prevent and control hypertension. 1 . Methods and an overview of the Canadian recommendations. Canadian hypertension society, Canadian coalition for high blood pressure prevention and control, laboratory centre for disease control at health Canada, heart and stroke foundation of Canada. CMAJ 1999;160:S1-6.

21. Ale OK, Braimoh RW, Adebiyi A, Ajuluchukwu JN. Lifestyle modification and hypertension: prescription patterns of Nigerian general practitioners. Pan Afr Med J 2020;35:130

22. Erskine S. The Impact of Culturally-Tailored Education on Knowledge and Behavior Related to Screening and Lifestyle Management of Blood Pressure in African Immigrants; 2020.

23. Sacks FM, Svetkey LP, Vollmer WM, Appel LJ, Bray GA, Harsha D, et al. Effects on blood pressure of reduced dietary sodium and the dietary approaches to stop hypertension (DASH) diet. N Engl J Med 2001;344:3-10

24. Svetkey LP, Simons-Morton D, Vollmer WM, Appel LJ, Conlin PR, Ryan DH, et al. Effects of dietary patterns on blood pressure: Subgroup analysis of the Dietary Approaches to Stop Hypertension (DASH) randomized clinical trial. Arch Intern Med 1999;159:285-93.

25. Mochizuki S, Dahlof B, Shimizu M, Ikewaki K, Yoshikawa M, Taniguchi I, et al. Valsartan in a Japanese population with hypertension and other cardiovascular disease (Jikei Heart Study): A randomised, open-label, blinded endpoint morbidity-mortality study. Lancet 2007;369:1431-9.

26. Handa T, Nagai S, Miki S, Fushimi Y, Ohta K, Mishima M, et al. Incidence of pulmonary hypertension and its clinical relevance in patients with sarcoidosis. Chest 2006;129:1246-52.

27. Tibebu A, Mengistu D, Negesa L. Adherence to recommended lifestyle modifications and factors associated for hypertensive patients attending chronic follow-up units of selected public hospitals in Addis Ababa, Ethiopia. Patient Prefer Adherence 2017;11:323.

28. Wondmieneh A, Gedefaw G, Getie A, Demis A. Self-care practice and associated factors among hypertensive patients in Ethiopia: A systematic review and meta-analysis. Int J Hypertens 2021;2021:5582547.

29. Alsairafi M, Alshamali K, Al-Rashed A. Effect of physical activity on controlling blood pressure among hypertensive patients from Mishref area of Kuwait. Eur J Gen Med 2010;7:377-84.

30. Pescatello LS, Franklin BA, Fagard R, Farquhar WB, Kelley GA, Ray CA. Exercise and hypertension. Med Sci Sports Exerc 2004;36:533-53

31. Pescatello LS. Exercise and hypertension: Recent advances in exercise prescription. Curr Hypertens Rep 2005;7:281-6. 